\title{
Extended infusion versus intermittent infusion of imipenem in the treatment of ventilator- associated pneumonia
}

This article was published in the following Dove Press journal:

Drug Design, Development and Therapy

6 September 2017

Number of times this article has been viewed

\author{
Mohamed M Ibrahim' \\ Tarek Fouad Tammam² \\ Mohy El Deen Ebaed ${ }^{3}$ \\ Hatem A Sarhan ${ }^{4}$ \\ Gamal F Gad ${ }^{5}$ \\ Amal K Hussein ${ }^{4}$ \\ 'Department of Clinical Pharmacy, \\ Faculty of Pharmacy, Minia University, \\ Minia, Egypt; ' ${ }^{2}$ epartment of \\ Anesthesia and Intensive Care, Faculty \\ of Medicine, Suez Canal University, \\ Ismailia, Egypt; ${ }^{3}$ Department of \\ Biochemistry, Egyptian Ministry of \\ Interior, Cairo, Egypt; ${ }^{4}$ Department \\ of Pharmaceutics, ${ }^{5}$ Department of \\ Microbiology and Immunology, Faculty \\ of Pharmacy, Minia University, Minia, \\ Egypt
}

Background: Mechanical ventilation support can be the main source of ventilator-associated pneumonia (VAP). VAP is a serious infection that may be associated with dangerous gramnegative bacteria mainly, and it leads to an increase in the mortality in the intensive care unit (ICU). Imipenem is one of the strongest antibiotics now available for treating VAP which is associated with gram-negative and gram-positive bacteria, and it belongs to beta-lactam antibiotic group (carbapenem).

Objective: This study tried to investigate the efficacy of imipenem against VAP when it was infused within 180 min versus the efficacy when it was infused within 30-60 min.

Setting: This study was conducted in main ICU in general hospital which consists of surgical and medical beds within 2 years. One hundred and eighty-seven patients were enrolled on it.

Method: This study is a retrospective cohort which was conducted within 2 years. The efficacy of imipenem which was administered by intermittent infusion (30-60 min) within first year was compared with the efficacy of imipenem which was administered by extended infusion (180 min) within second year in the field of VAP curing and cost reduction. All data were collected retrospectively from patient medical files and were statistically analyzed by SPSS version 20 .

Main outcome: The study was designed to measure clinical and cost reduction outcomes, mortality and hospital stay.

Results: The results indicated that there is a significant decrease in mortality, number of recurrent infection, and ICU stay length, and the number of mechanical ventilator days was associated with extended imipenem infusion during the second year of the study.

Conclusion: The use of imipenem with extended infusion over 3 hours enhances its clinical outcomes in the treatment of VAP.

Keywords: carbapenem, imipenem, VAP, extended infusion, intermittent infusion

\section{Introduction}

Ventilator-associated pneumonia (VAP) is a serious form of lung infection among intensive care unit (ICU) patients that results from mechanical ventilation support. ${ }^{1}$ Also, it is a major source of mortality among these critically ill patients with rates as high as $24 \%-76 \%$ reported at a variety of institutions. Critically ill ventilated patients with VAP have (2-10)-fold higher risk of death compared with patients without VAP. VAP complicates the course of treatment for patients ( $8 \%-28 \%)$ who receive mechanical ventilation, ${ }^{2-4}$ and it can be diagnosed by a combination of several radiographic, clinical, and laboratory evidences, ${ }^{5,6}$ such as body temperature greater than $38.3^{\circ} \mathrm{C}$ or less than $36^{\circ} \mathrm{C}$, white blood cell count greater than $10,000 / \mathrm{mm}^{3}$ or less than $4,000 / \mathrm{mm}^{3}$, purulent secretions, increased secretions, or change in secretions.
Correspondence: Amal K Hussein Department of Clinical Pharmacy, Faculty of Pharmacy, Minia University, El Omoumy Road, Ard Shalaby, Minia 61519, Egypt

Tel + I I 20 I09 205 I05 I

Email amal_ka@yahoo.com 
Also, positive tracheal cultures or bronchoalvelolar lavage (BAL) cultures can be used for diagnosis of VAP. ${ }^{7}$ Moreover, VAP can be diagnosed with some signs of respiratory distress, such as shortness of breath, rapid breathing, and abnormal breathing sounds when listening by chest auscultation, increased need for oxygen on the ventilator, and at least two serial chests' X-rays showing sustained or worsening shadowing (infiltrates or consolidations).

Gram-negative bacterial infections are a very important issue in health care-associated infections, especially in pneumonia caused by VAP. ${ }^{8,9}$ Many studies have demonstrated a significant relationship between VAP attributed to multidrug-resistant gram-negative bacteria (MDR-GNB) and greater mortality rates. ${ }^{10-12}$ Furthermore, MDR-GNB is more likely to be treated with an inappropriate initial antibiotic regimen, which in part explains the higher mortality rate associated with these infections. ${ }^{13,14}$ According to our ICU settings microorganism occurrence, the gram-negative bacteria are the leading source of VAP infections. This finding is in parallel with other worldwide data in the same infection area. ${ }^{15}$ In this study, a combination of imipenem with cilastatin, which has high efficacy to gram-negative bacteria, was used according to our antibiogram. Imipenem is a member of carbapenem group with broad spectrum activity against gram-positive and gram-negative bacteria. Therefore, imipenem is used in empirical therapy to a lot of infection caused by different bacteria. ${ }^{16,17}$ Infectious Diseases Society of America (IDSA) reported that extended infusion is an ideal way to optimize beta-lactams antibiotic efficacy. ${ }^{18}$ The activity of imipenem, like other beta-lactams antibiotic, depends on the time of infusion. Therefore, this study compared the efficacy of imipenem when used as intermittent infusion and also when used as extended infusion to figure out if this recommended method has any clinical impact both in curing VAP and also in total cost reduction or not.

\section{Aim of the study}

To investigate the clinical and cost reduction efficacy of imipenem against VAP when it was infused within $180 \mathrm{~min}$ versus the efficacy when it was infused within 30-60 min and its impact on mortality and hospital stay.

\section{Ethics approval}

This study is a retrospective cohort study; in this type of study, formal consent is not required. All data were collected from patients' files without any interference in patient treatment plans. As this is a retrospective cohort study, the Ethics Committee of Minia University judged that it did not require ethical approval and patient consent, and also patient confidentiality has been maintained; all data were anonymized.

\section{Method}

This study is a retrospective cohort study on adult ICU patients with VAP. The study was conducted in 25-beds ICU which consists of 14 medical beds and 11 surgical beds in a general hospital. The 2-year study period was between January 2013 and December 31, 2014. All data were collected from antimicrobial approval sheet; patient medical file which had all information about infection, mortality, and hospital admission and stay records; and patient daily progress sheets. Data collected before December 31, 2013, were compared with data that collected after December 31, 2013, until December 31, 2014. The data were analyzed by IBM SPSS program version 20.

In period between January 2013 and December 2013, most of the patients received imipenem to treat VAP by intermittent infusion; on the other hand, in the period between January 2014 and December 2014, most of the patients received imipenem by extended infusion. So, our study objective is to investigate which method will be more effective clinically and financially.

\section{Patient}

In the study period, 891 patients with VAP were scrutinized and dispositioned based on inclusion criteria where 563 patients had gram-negative and 509 patients had gram-negative organisms sensitive to imipenem, and only 187 patients fulfilled all inclusion criteria for study.

\section{Antimicrobial agent}

The only carbapenem used in this study was imipenem with cilastatin which came with agreement from our local epidemiology antibiogram for highest sensitivity for gram-negative bacteria. Imipenem dose is $500 \mathrm{mg}$ every 6 hours or $1 \mathrm{~g}$ every 3 hours, not exceeding $4 \mathrm{~g}$ per day. The lower dose was used in patients less than $70 \mathrm{~kg}$ and with renal impairment, and same dose regimen was administered to both groups, see Table $1 .{ }^{19}$ Imipenem plasma protein binding is $13 \%-21 \%$, and cilastatin plasma protein binding is $40 \%$. Imipenem is

Table I Adjustment of imipenem $1.5 \mathrm{~g}$ per day dose for renal impairment patients with weight $40 \mathrm{~kg}$

\begin{tabular}{llll}
\hline & CrCL $\left(\mathrm{mL} / \mathrm{min} / 1.73 \mathbf{~ m}^{2}\right)$ & Dose $(\mathbf{m g})$ & Intervals $(\mathbf{h})$ \\
\hline $\mathrm{I}$ & $\geq 7 \mathrm{I}$ & 250 & 8 \\
2 & $4 \mathrm{I}-70$ & 125 & 6 \\
3 & $21-40$ & 125 & 8 \\
4 & $\leq 20$ & 125 & 12 \\
\hline
\end{tabular}


Table 2 MIC of imipenem range for gram-negative bacteria

\begin{tabular}{llllll}
\hline Organism & Pseudomonas & Klebsiella & E. coli & Acinetobacter & Others \\
\hline MIC $(\mu \mathrm{g} / \mathrm{mL})$ of imipenem & $0.5-4$ & $0.06-0.5$ & $0.06-0.25$ & $1-8$ & $0.25-8$ \\
\hline
\end{tabular}

metabolized in the kidney by dehydropeptidase- 1 whose activity is blocked by cilastatin. The half-life of both drugs is $60 \mathrm{~min}$, and it is prolonged with renal impairment. It was reported that $70 \%$ of unchanged drug was excreted in urine (both drugs). ${ }^{20-22}$

\section{Microorganism prevalence}

In total, 386 isolates were gram-negative infection with MIC range, which are shown in Table 2 and prevalence percentage to each organism shown in Table 3.

\section{Inclusion criteria}

- Patients were diagnosed with VAP.

- Patient had VAP caused only by gram-negative bacteria and sensitive to imipenem or intermediate with no sensitivity to other antibiotics screened in the extended infusion period.

- Patients started imipenem within 48 hours after culture sensitive for imipenem.

- Patients started imipenem empirically, and culture results came with gram-negative pathogens which were sensitive to imipenem, so patients continued on imipenem.

- Patients started course of treatment on imipenem over 4 days.

\section{Exclusion criteria}

- Isolates that showed resistance to imipenem.

- Patients start any beta-lactam for treatment of VAP and shifted to imipenem before culture.

- Patients start on intermittent or at take one dose by intermittent infusion in the period of the extended infusion.

- Patients with multiple organisms covered by other drug(s) with imipenem.

- Patients with VAP caused by organisms other than gramnegative.

Table 3 Gram-negative bacterial prevalence during study

\begin{tabular}{llll}
\hline $\begin{array}{l}\text { Microorganism isolates } \\
\text { prevalence \% }\end{array}$ & $\begin{array}{l}\text { Extended } \\
\text { infusion } \\
\text { period (\%) }\end{array}$ & $\begin{array}{l}\text { Intermittent } \\
\text { infusion } \\
\text { period (\%) }\end{array}$ & P-value \\
\hline Pseudomonas species & 28 & 25 & 0.82 \\
Klebsiella species & 35 & 29 & 0.76 \\
E. coli & 18 & 22 & 0.80 \\
Acinetobacter species & 11 & 15 & 0.78 \\
Other gram-negative bacteria & 8 & 9 & 0.85 \\
\hline
\end{tabular}

- Patients with no culture on starting (empirically) and no growth and no culture after 3 days.

- Patients who started imipenem after 48 hours after positive culture sensitivity for imipenem.

- Patients who did not complete 4 days from starting imipenem.

- Patients allergic to imipenem or cilastatin.

\section{Results}

In the present study, 187 patients were fit for inclusion criteria. Patients' age was between 29 and 76 years old; the number of female was 86 patients and patient BMI was between 18 and 48. In total, 124 patients were from Middle East, 59 patients were Asian, and 4 patients had other ethnicities, as shown in Table 4.

Table 4 Demographic data

\begin{tabular}{|c|c|c|c|}
\hline Demographic data & $\begin{array}{l}\text { Extended } \\
\text { infusion }\end{array}$ & Intermittent & $P$-value \\
\hline Age (year) & $55 \pm I I .4$ & $61 \pm 14.2$ & 0.76 \\
\hline Gender (female) & $47(48)$ & $39(44)$ & 0.79 \\
\hline \multicolumn{4}{|l|}{ Ethnicity } \\
\hline Middle East & $63(64)$ & $61(68.5)$ & 0.77 \\
\hline Asian & $32(33)$ & $27(30.3)$ & 0.75 \\
\hline Others & $3(3)$ & $\mathrm{I}(\mathrm{I} .2)$ & 0.06 \\
\hline BMI & $24 \pm 3$ & $22.5 \pm 2.9$ & 0.66 \\
\hline \multicolumn{4}{|l|}{ Comorbidities } \\
\hline Respiratory (not VAP) & $14(14)$ & II (I2) & 0.70 \\
\hline Cardiovascular & $33(34)$ & $35(39)$ & 0.69 \\
\hline Immunodeficiency & $3(3)$ & $I(I)$ & 0.07 \\
\hline CNS & $2(2)$ & $4(4)$ & 0.08 \\
\hline Oncology & $I(I)$ & $\mathrm{I}(\mathrm{I})$ & 0.65 \\
\hline Hematology & $7(7)$ & $5(6)$ & 0.77 \\
\hline Liver & $24(24)$ & $18(20)$ & 0.43 \\
\hline Renal & $29(30)$ & $22(25)$ & 0.5 \\
\hline Baseline SOFA score & $11.34 \pm 1.98$ & $10.95 \pm 1.78$ & 0.85 \\
\hline $\begin{array}{l}\text { Patient start empirically with } \\
\text { inclusion criteria }\end{array}$ & $42(43)$ & $38(43)$ & 0.84 \\
\hline $\begin{array}{l}\text { Days in ICU before } \\
\text { developing VAP (days) }\end{array}$ & $3.98 \pm 1.32$ & $4.45 \pm 1.66$ & 0.83 \\
\hline \multicolumn{4}{|c|}{ Site of sample taking for screening VAP infection } \\
\hline ETT or tracheostomy tube & $28(29)$ & $31(35)$ & 0.79 \\
\hline Sputum & $46(47)$ & $39(44)$ & 0.79 \\
\hline BAL & $21(2 I)$ & $15(17)$ & 0.82 \\
\hline Others & $3(3)$ & $4(4)$ & 0.85 \\
\hline $\begin{array}{l}\text { Patients who had more than } \\
\text { one gram-negative organism } \\
\text { all sensitive to imipenem }\end{array}$ & $25(26)$ & $18(20)$ & 0.79 \\
\hline
\end{tabular}


Table 5 Clinical outcomes of study results

\begin{tabular}{|c|c|c|c|}
\hline Outcome data & $\begin{array}{l}\text { Extended } \\
\text { infusion }(n=98)\end{array}$ & $\begin{array}{l}\text { Intermittent } \\
(n=89)\end{array}$ & $P$-value \\
\hline Mortality & $4(4)$ & $18(20)$ & 0.03 \\
\hline $\begin{array}{l}\text { Recurrent infection with } \\
\text { the same organisms }\end{array}$ & $2(2)$ & $13(14)$ & 0.04 \\
\hline ICU stay (days) & $9.59 \pm 2.12$ & $15.34 \pm 3.75$ & 0.04 \\
\hline Mechanical ventilator (days) & $9.32 \pm 2.3$ & $|5.1| \pm 3.78$ & 0.045 \\
\hline $\begin{array}{l}\text { Cost related to infection } \\
\text { (\$) per patient }\end{array}$ & $5,430 \pm 893$ & $9,800 \pm 1,345$ & 0.31 \\
\hline $\begin{array}{l}\text { Total hospital cost } \\
\text { (\$) per patient }\end{array}$ & $10,110 \pm 1,853$ & $18,330 \pm 4,854$ & 0.26 \\
\hline
\end{tabular}

Note: Data presented as mean \pm standard deviation or $\mathrm{n}(\%)$.

Cardiovascular, renal, and hepatic problems were the most common comorbidities associated with patients in the two study groups, and also most common site of sample collection was ETT, tracheostomy tube, sputum, and BAL, as shown in Table 4.

Baseline SOFA score (Sepsis-related organ failure assessment score) for intermittent infusion patients was $11.34 \pm 1.98$ but baseline SOFA score for extended infusion patients was 10.95 \pm 1.78 , as shown in Table 4 .

About mortality, only 4 patients died by VAP during the second year (extended infusion), compared to 18 patients during the first year $(P$-value $=0.03)$, see Table 5 and Figure 1.

Only 2 patients had rebound infection compared to 13 patients during the first year $(P$-value $=0.04)$ as shown in Table 5 and Figure 2. Furthermore, ICU stay during the second year was $9.59 \pm 2.12$ days compared to $15.34 \pm 3.75$ days during the first year $(P$-value $=0.04)$, as shown in Table 5 and Figure 3. Finally, the mechanical ventilation duration time during the second year was $9.32 \pm 2.3$ days compared to first year (15.11 \pm 3.78$)$ days with $P$-value (0.045); the details are shown in Table 5 and Figure 4.

The cost related to infection per patient at the second year was 5,430 \pm 893 USD whereas at the first year was $9,800 \pm 1,345$ USD, as shown in Table 5 and Figure 5. The total

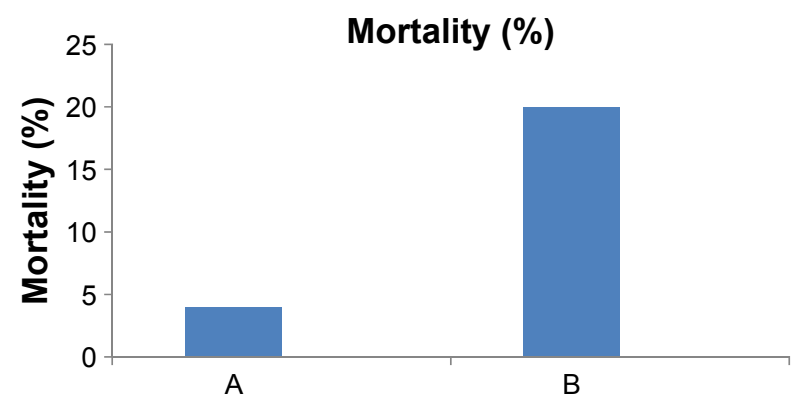

Figure I Percentage of mortality: (A) extended infusion, (B) intermittent infusion.

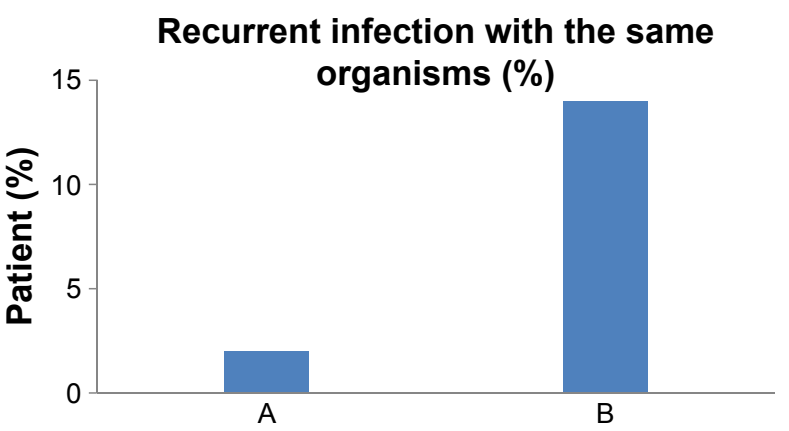

Figure 2 Percentage of patients who had recurrent infection with the same microorganism.

Note: (A) extended infusion, (B) intermittent infusion.

hospital cost per patient at the second year was $10,110 \pm 1,853$ USD whereas at the first year was $18,330 \pm 4,854$ USD; the details are shown in Table 5 and Figure 6.

\section{Discussion}

In our hospital settings, antimicrobial resistance especially for gram-negative bacteria was dramatically increased. Innovative polices and technique like enhancing PK/PD and antibiotic cycling were implemented to inhibit antimicrobial resistance and increasing antibiotic efficacy. In the present study, we evaluate the benefits of increasing infusion time to be extended infusion rather than intermittent infusion to enhance antibiotic pharmacodynamics. These approaches were approved by many studies. Beta-lactams are time-dependent antibiotics, and their activity increases by increasing exposure time. ${ }^{23}$

In this 2-year study, at the first year (1 January to 31 December 2013), beta-lactam antibiotic (carbapenem and imipenem) had been used by intermittent 30-60-min infusion, whereas at the second year (1 January to 31 December 2014) beta-lactam (imipenem) had been used by extended infusion over 3-hours infusion.

Non-significant difference was observed between 2 years in baseline SOFA scores $(P$-value $=0.85)$, this means that the two study arms had patients in same ill status conditions.

Non-significant difference was observed between the groups of the study in age, gender, ethnicity background,

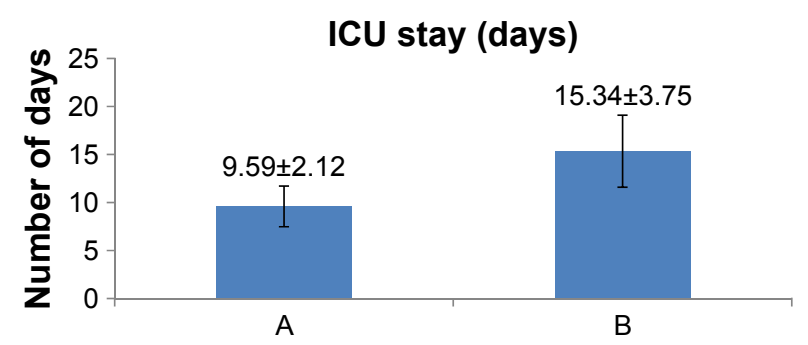

Figure 3 ICU stay (days): (A) extended infusion, (B) intermittent infusion. 


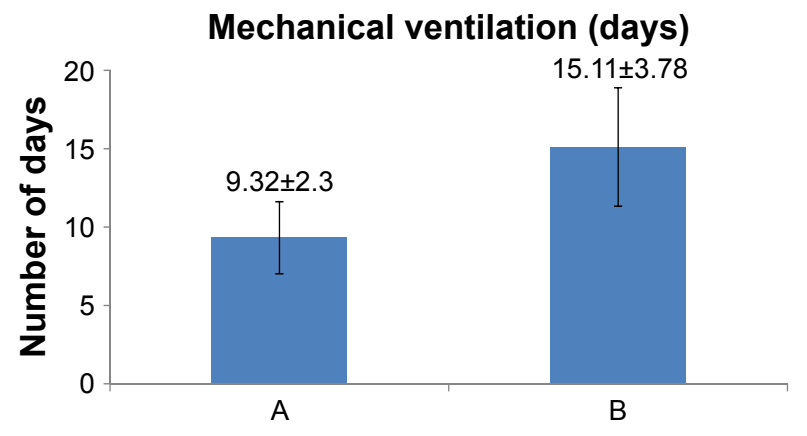

Figure 4 Mechanical ventilation (days): (A) extended infusion, (B) intermittent infusion.

and BMI, this indicates that the patients in two groups had the same demographic features.

Non-significant difference was found between the two groups in the number of samples which were collected from sputum, BAL, ETT, tracheostomy tube, and other sites. A non-significant difference was found between the two groups in the number of patients who started imipenem as empirical therapy with same inclusion criteria, in number of days before the development of VAP, and in number of patients who had more than one gram-negative bacteria and sensitive to imipenem.

Non-significant difference was found between the two groups in percentage of prevalence of different gram-negative species whereas more prevalent ones were Pseudomonas species, Klebsiella species, and E. coli and Acinetobacter species, as shown in Table 3 and Figure 7; this approved that almost the two study arms had same preexisting conditions.

The clinical results revealed a significant decrease in mortality rate with second year, often this was due to improving in VAP condition; these results agree with results observed by Lodise TP who performed a cohort study of patients who received piperacillin-tazobactam therapy for a Pseudomonas aeruginosa infection that was susceptible to piperacillin-tazobactam during the period January 2000 to June 2004. Prior to February 2002, all patients received

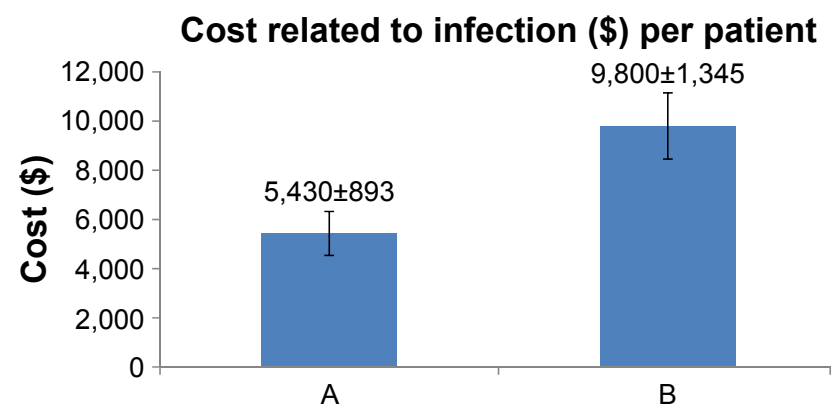

Figure 5 Cost related to infection per American dollar per patient. Note: (A) extended infusion, $(\mathbf{B})$ intermittent infusion.

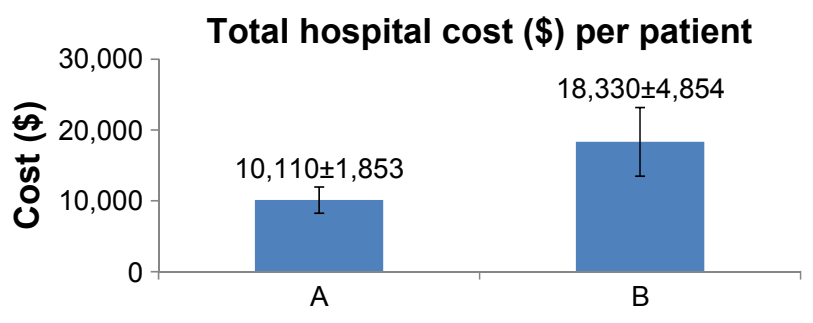

Figure 6 Total hospital cost reduction per American dollar per patient. Note: (A) extended infusion, (B) intermittent infusion.

intermittent infusions of piperacillin-tazobactam (3.375 g intravenously for 30 min every 4 or 6 hours); after this time, all patients received extended infusions of piperacillintazobactam ( $3.375 \mathrm{~g}$ intravenously for 4 hours every 8 hours) and results observed Yost who stated that pharmacodynamic dosing using extended-infusion piperacillin-tazobactam demonstrated favorable outcomes, including mortality, when compared with nonextended-infusion, similar-spectrum beta-lactams in the treatment of patients with documented gram-negative infections. ${ }^{24,25}$

Significant decrease in rebound infection by the same microorganism was reported during the second year; this is because of increasing the efficacy of imipenem in gramnegative bacteria eradication.

Significant decrease in ICU stay length which was caused by VAP infection with second year, a significant decrease was in mechanical ventilation days during second year was reported when compared with same results at first year and a non-significant decrease in cost either related or not related between 2 years were reported, all these findings are due to increasing efficacy of imipenem in the treatment of VAP. These results strongly agree with results which observed in hospital stay-related infection by Nicasio et al who concluded that in their ICUs where multidrug-resistant bacteria are common, an approach considering ICU-specific antibiotic MICs coupled with pharmacodynamic dosing strategies resulted in improved outcomes and shorter duration of treatments. ${ }^{26}$

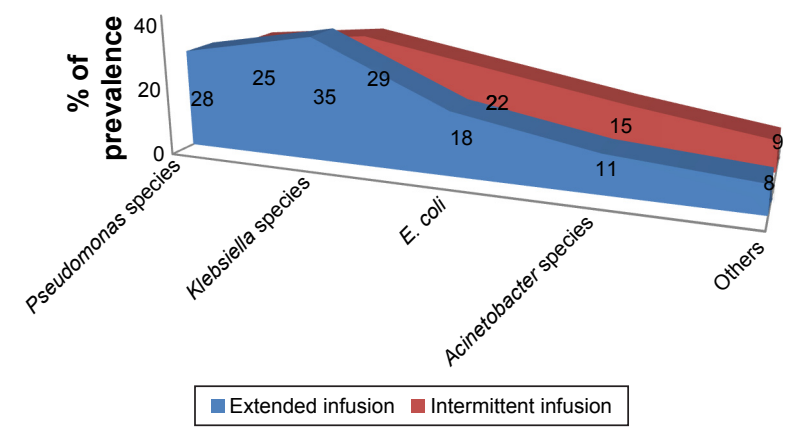

Figure 7 Prevalence for gram-negative bacteria. 


\section{Conclusion}

Extended infusion was implemented to improve the PK/PD profile of imipenem as a means to maximize its therapeutic benefit against imipenem-responsive gram-negative-caused VAP in our ICU facility. Significant reduction of mortality rates, infection duration, mechanical ventilation time, and ICU stay length with the new extended infusion protocol when compared to the previous intermittent infusion protocol was achieved. This approach can therefore be recommended to treat VAP on a wider health care scale.

\section{Disclosure}

The authors report no conflicts of interest in this work.

\section{References}

1. Michetti CP, Fakhry SM, Ferguson PL, Cook A, Moore FO, Gross R; AAST Ventilator-Associated Pneumonia Investigators. Ventilatorassociated pneumonia rates at major trauma centers compared with a national benchmark: a multi-institutional study of the AAST. J Trauma Acute Care Surgery. 2012;72(5):1165-1173.

2. Langer M, Mosconi P, Cigada M, Mandelli M. Long-term respiratory support and risk of pneumonia in critically ill patients. Am Rev Respir Dis. 1989;140(2):302-305.

3. Torres A, Aznar R, Gatell JM, et al. Incidence, risk, and prognosis factors of nosocomial pneumonia in mechanically ventilated patients. Am Rev Respir Dis. 1990;142(3):523-528.

4. Craven DE, Kunches LM, Kilinsky V, Lichtenberg DA, Make BJ, McCabe WR. Risk factors for pneumonia and fatality in patients receiving continuous mechanical ventilation. Am Rev Respir Dis. 1986; 133(5):792-796.

5. Chastre J, Fagon JY, Bornet-Lecso M, et al. Evaluation of bronchoscopic techniques for the diagnosis of nosocomial pneumonia. Am J Respir Crit Care Med. 1995;152(1):231-240.

6. Chastre J, Fagon JY, Trouillet JL. Diagnosis and treatment of nosocomial pneumonia in patients in intensive care units. Clin Infect Dis. 1995;21(Supplement 3):S226-S237.

7. Kollef MH, Vlasnik JO, Sharpless L, Pasque C, Murphy D, Fraser V. Scheduled change of antibiotic classes: a strategy to decrease the incidence of ventilator-associated pneumonia. Am J Respir Crit Care Med. 1997;156(4):1040-1048.

8. American Thoracic Society, Infectious Diseases Society of America. Guidelines for the management of adults with hospital-acquired, ventilator-associated, and healthcare-associated pneumonia. Am J Respir Crit Care Med. 2005;171(4):388.

9. Kollef MH, Shorr A, Tabak YP, Gupta V, Liu LZ, Johannes RS. Epidemiology and outcomes of health-care-associated pneumonia: results from a large US database of culture-positive pneumonia. Chest $J$. 2005;128(6):3854-3862.
10. Fagon JY, Chastre J, Hance AJ, Montravers P, Novara A, Gibert C. Nosocomial pneumonia in ventilated patients: a cohort study evaluating attributable mortality and hospital stay. Am J Med. 1993;94(3): 281-288.

11. Diaz E, Munoz E, Agbaht K, Rello J. Management of ventilatorassociated pneumonia caused by multiresistant bacteria. Curr Opin Crit Care. 2007;13(1):45-50.

12. Garnacho-Montero J, Ortiz-Leyba C, Fernández-Hinojosa E, et al. Acinetobacter baumannii ventilator-associated pneumonia: epidemiological and clinical findings. Intensive Care Med. 2005;31(5):649-655.

13. Kollef MH. Inadequate antimicrobial treatment: an important determinant of outcome for hospitalized patients. Clin Infect Dis. 2000; 31(Supplement 4):S131-S138.

14. Mueller EW, Hanes SD, Croce MA, Wood GC, Boucher BA, Fabian TC. Effect from multiple episodes of inadequate empiric antibiotic therapy for ventilator-associated pneumonia on morbidity and mortality among critically ill trauma patients. J Trauma Acute Care Surg. 2005;58(1):94-101.

15. Spencer RC. Predominant pathogens found in the European prevalence of infection in intensive care study. Eur J Clin Microbiol Infect Dis. 1996;15(4):281-285.

16. Birnbaum J, Kahan FM, Kropp H, Macdonald JS. Carbapenems, a new class of beta-lactam antibiotics: discovery and development of imipenem/cilastatin. Am J Med. 1985;78(6):3-21.

17. Kropp H, Gerckens L, Sundelof JG, Kahan FM. Antibacterial activity of imipenem: the first thienamycin antibiotic. Rev Infect Dis. 1985; 7(Supplement 3):S389-S410.

18. Dellit TH, Owens RC, McGowan JE, et al. Infectious Diseases Society of America and the Society for Healthcare Epidemiology of America guidelines for developing an institutional program to enhance antimicrobial stewardship. Clin Infect Dis. 2007;44(2):159-177.

19. Mouton JW, Touw DJ, Horrevorts AM, Vinks AA. Comparative pharmacokinetics of the carbapenems. Clin Pharmacokinet. 2000;39(3): 185-201.

20. Balfour JA, Bryson HM, Brogden RN. Imipenem/cilastatin. An update of its antibacterial activity, pharmacokinetics and therapeutic efficacy in the treatment of serious infections. Drugs. 1996;51(1):99-136.

21. Alván G, Nord CE. Adverse effects of monobactams and carbapenems. Drug Safety. 1995;12(5):305-313.

22. Drusano GL. Prevention of resistance: a goal for dose selection for antimicrobial agents. Clin Infect Dis. 2003;36(Supplement 1):S42-S50.

23. Craig WA. Interrelationship between pharmacokinetics and pharmacodynamics in determining dosage regimens for broad-spectrum cephalosporins. Diagn Microbiol Infect Dis. 1995;22(1-2):89-96.

24. Lodise TP, Lomaestro B, Drusano GL. Piperacillin-tazobactam for Pseudomonas aeruginosa infection: clinical implications of an extendedinfusion dosing strategy. Clin Infect Dis. 2007;44(3):357-363.

25. Yost RJ, Cappelletty DM. The Retrospective Cohort of ExtendedInfusion Piperacillin-Tazobactam (RECEIPT) study: a multicenter study. Pharmacotherapy. 2011;31(8):767-775.

26. Nicasio AM, Eagye KJ, Nicolau DP, et al. Pharmacodynamic-based clinical pathway for empiric antibiotic choice in patients with ventilatorassociated pneumonia. J Crit Care. 2010;25(1):69-77.
Drug Design, Development and Therapy

\section{Publish your work in this journal}

Drug Design, Development and Therapy is an international, peerreviewed open-access journal that spans the spectrum of drug design and development through to clinical applications. Clinical outcomes, patient safety, and programs for the development and effective, safe, and sustained use of medicines are the features of the journal, which

\section{Dovepress}

has also been accepted for indexing on PubMed Central. The manuscript management system is completely online and includes a very quick and fair peer-review system, which is all easy to use. Visit http://www.dovepress.com/testimonials.php to read real quotes from published authors. 